\title{
Clinical effect of long-term administration of tolvaptan in patients with heart failure and chronic kidney disease
}

\author{
Yohei Ono ${ }^{1, *}$, Hiroto Takamatsu ${ }^{1}$, Masahiro Inoue ${ }^{1}$, Yukio Mabuchi ${ }^{1}$, Tetsuya Ueda ${ }^{1}$, \\ Tadashi Suzuki ${ }^{1}$, Masahiko Kurabayashi ${ }^{2}$ \\ ${ }^{1}$ Department of Cardiology, Fujioka General Hospital, Gunma, Japan; \\ ${ }^{2}$ Gunma University Hospital, Department of Cardiovascular Medicine, Gunma, Japan.
}

\begin{abstract}
Summary The effectiveness of long-term administration of tolvaptan in heart failure (HF) patients with chronic kidney disease (CKD) has not been fully studied. Hence, in this study, we investigated the effects of chronic administration of tolvaptan on patients with $\mathrm{HF}$ and CKD. We consecutively enrolled 31 patients with acute HF syndrome (AHFS) who were administrated tolvaptan as a long-term medication (TLV group). All patients had a history of prior HF admission and CKD. We also consecutively enrolled 27 patients with AHFS, a prior history of $\mathrm{HF}$ and CKD (conventional group). We compared renal function and outcomes between the two groups at discharge for AHFS and after 6 months of followup. The estimate glomerular filtration rate (eGFR) was maintained at approximately the same level in the TLV group exhibited approximately the same eGFR $(-1.1 \pm 8.3 \mathrm{~mL} /$ $\left.\min / 1.73 \mathrm{~m}^{2}\right)$ but decreased in the conventional group $\left(-7.4 \pm 10.4 \mathrm{~mL} / \mathrm{min} / 1.73 \mathrm{~m}^{2}\right)$. There was a significant difference in the changes observed in eGFR between the conventional and TLV groups $(p=0.01)$. There were no significant differences in the frequencies of rehospitalization and death. Long-term administration of tolvaptan may prevent increased renal dysfunction in HF patients with CKD. This conclusion should be confirmed in a largescale prospective study.
\end{abstract}

Keywords: Heart failure treatment, diuretic, renal dysfunction

\section{Introduction}

Diuretics are an important therapeutic tool for managing heart failure (HF) patients. In particular, loop diuretics are a mainstream therapy that act by reducing fluids in patients with acute HF by inhibiting sodium reabsorption in the loop of Henle. By increasing the distal tubular delivery of sodium, loop diuretics activate the renin-angiotensin system, which causes vasoconstriction of the afferent arteriole and a reduction in renal blood flow. Loop diuretics also activate the sympathetic nervous system, resulting in poor outcomes (1-3). Moreover, the use of loop diuretics can lead to serum potassium depletion, which can promote arrhythmias $(4,5)$. Thus, loop diuretics are associated

\footnotetext{
*Address correspondence to:

Dr. Yohei Ono, Department of Cardiology, Fujioka General Hospital, 942-1 Fujioka, Fujioka, Gunma 375-8503, Japan. E-mail: y-ono@fujioka-hosp.or.jp
}

with poor outcomes that are broadly predictive of death and morbidity ( 6 ).

Tolvaptan is a selective vasopressin $\mathrm{V}_{2}$ receptor antagonist that disturbs the movement of aquaporin 2 to the luminal side of cortical collecting duct cells by activating cyclic adenosine monophosphate (cAMP). In addition, tolvaptan inhibits the reabsorption of water and produces water diuresis through a relatively recently identified mechanism of action $(7,8)$.

Tolvaptan is an alternative to the use of loop diuretics that is expected to slow the progression of renal failure and improve the prognosis of HF patients. Specifically, tolvaptan exerts a protective effect on the kidney by initiating a diuretic effect without activating the renin-angiotensin system $(1,2)$. Additionally, it has been shown that renal blood flow and the glomerular filtration rate (GFR) are not reduced by tolvaptan (9). Hence, it has been suggested that tolvaptan administration reduces the risk of a decline in renal function in patients with acute HF syndrome (AHFS) 
(10). Tolvaptan has been shown to be quick-acting when used to treat HF and was used in ACTIVE (11) and EVEREST (a test of the efficacy of vasopressin antagonism in HF outcomes study) $(12,13)$ studies. However, the primary mechanisms underlying the effects of tolvaptan on renal function have not been determined, and few reports have evaluated its efficacy when administered chronically. In the EVEREST, there was no significant improvement in two primary endpoints of all-cause mortality or in the rate of cardiovascular death or hospitalization for HF (14).

However, the results of post-marketing surveillance in Japan demonstrated that $30 \%$ of patients with HF were also administered tolvaptan for greater than 2 weeks (15). In clinical practice, some patients require chronic administration of tolvaptan. In this study, we investigated the effects of long-term administration of tolvaptan in patients with HF and chronic kidney disease (CKD).

\section{Materials and Methods}

\subsection{Study population}

This report is a retrospective observational study with no planned protocol. Thirty-one ADHF patients who were administered tolvaptan for 6 months or more from January 2013 to December 2016 were consecutively enrolled in the study. Twenty-seven HF patients with CKD and a past history of admission for HF from January 2013 to December 2016 were also consecutively enrolled. We compared the 31 patients with ADHF (TLV group) to the 27 patients with ADHF and CKD (conventional group).

\subsection{Data collection}

All data were collected retrospectively. Data from laboratory tests included serum creatinine (Cre) levels, serum concentrations of sodium, serum concentrations of potassium, and brain-type natriuretic peptide (BNP) levels. Tests were conducted at admission for ADHF (baseline), at discharge from ADHF and after a 6-months follow-up period. The estimate glomerular filtration rate (eGFR) was calculated using equation coefficients obtained from the modification of diet in renal disease (MDRD) study, which was performed in a Japanese population (16). CKD was defined as a syndrome

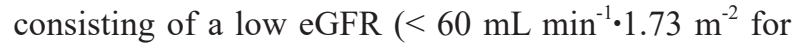
longer than 3 months (17). Based on the results of a previous study, we considered $20 \mathrm{mg}$ furosemide to be equivalent to approximately $30 \mathrm{mg}$ azosemide (18).

\subsection{Outcomes}

We evaluated renal function, dose changes in orally administered diuretics, New York Heart Association
(NYHA) classification, ejection fraction (EF) and BNP before and at 6 months after discharge from ADHF.

\subsection{Statistical analysis}

All data were statistically analyzed using a standard statistical software package (StatMate IV ATMS Co., Ltd., Tokyo, Japan). All numerical data are expressed as the mean \pm standard deviation. Unpaired Student's $t$-test or the Mann-Whitney U test was used to compare two groups. Categorical variables are expressed as a number (percent) and were compared by the chi-square or Fisher exact test. One-way analysis of variance (ANOVA) was used to detect significant factors among three or more groups. A $p$-value $<0.05$ was considered statistically significant.

\section{Results}

\subsection{Patients characteristics}

Table 1 shows the baseline clinical characteristics of the conventional and TLV groups. These data were collected at hospital admission for ADHF. There were no significant differences in age, medications, Cre, eGFR and echocardiographic data between the two groups. eGFR at baseline was equivalent in both groups. All patients had a previous history of HF and CKD.

The treatments administered during the acute phase are shown in Table 2. There were no significant differences in the daily dose of furosemide between the conventional and TLV groups. Similarly, there were no significant differences in the inotropic agents used between the two treatment groups.

No side effects were observed, and no patients discontinued tolvaptan in the TLV group. The treatments administered during the chronic phase are shown in Table 3. Concomitant medications included angiotensin-converting enzyme inhibitors, angiotensin receptor blockers, $\beta$-blockers, calcium blockers, loop diuretics, spironolactone, thiazide diuretics, and inotropic agents and were not significantly different between the conventional and TLV groups.

\subsection{Changes in renal function}

The changes in renal function observed during the study are shown in Table 4. At the time of hospital discharge, eGFR and Cre had not significantly worsened since admission in either group. However, eGFR had significantly declined in the conventional group at 6 months after discharge $(p=0.001)$. A comparison of the changes observed in eGFR between discharge and 6 months follow-up in the conventional and TLV groups is shown in Figure 1. In the TLV group, eGFR remained approximately the same $(-1.1 \pm 8.3)$, whereas in the 
Table 1. Comparisons of clinical characteristics, hemodynamics, laboratory data and underlying heart disease at baseline

\begin{tabular}{|c|c|c|c|}
\hline Items & Conventional group, $n=27$ & TLV group, $n=31$ & $p$-value \\
\hline Age (years) & $78.4 \pm 9.5$ & $76.0 \pm 14.2$ & 0.445 \\
\hline Gender/male & $12(44 \%)$ & $14(45 \%)$ & 1.000 \\
\hline BMI & $22.4 \pm 3.7$ & $21.2 \pm 3.7$ & 0.220 \\
\hline HT & $17(63 \%)$ & $17(55 \%)$ & 0.599 \\
\hline DM & $14(52 \%)$ & $9(29 \%)$ & 0.108 \\
\hline DL & $9(33 \%)$ & $7(32 \%)$ & 0.393 \\
\hline CKD & $27(100 \%)$ & $31(100 \%)$ & \\
\hline Prior PCI & $8(30 \%)$ & $6(19 \%)$ & 0.540 \\
\hline $\mathrm{S} / \mathrm{P} \mathrm{CABG}$ & $2(7 \%)$ & $1(3 \%)$ & 0.593 \\
\hline Prior HF & $27(100 \%)$ & $31(100 \%)$ & \\
\hline \multicolumn{4}{|l|}{ Hemodynamics } \\
\hline $\mathrm{SBP}(\mathrm{mmHg})$ & $140 \pm 36$ & $126 \pm 25$ & 0.095 \\
\hline DBP (mmHg) & $74 \pm 23$ & $68 \pm 17$ & 0.258 \\
\hline $\mathrm{HR}(/ \mathrm{bpm})$ & $86 \pm 28$ & $80 \pm 20$ & 0.370 \\
\hline $\operatorname{CS}(1 / 2 / 3 / 4 / 5)$ & $14 / 6 / 6 / 0 / 1$ & $7 / 17 / 5 / 0 / 2$ & 0.841 \\
\hline Nohria $(A / B / L / C)$ & $0 / 21 / 0 / 6$ & $0 / 28 / 0 / 3$ & 0.909 \\
\hline Killip $(1 / 2 / 3 / 4)$ & $0 / 4 / 22 / 1$ & $0 / 11 / 16 / 4$ & 0.878 \\
\hline NYHA (I/II/III/IV) & $0 / 0 / 2 / 25$ & $0 / 2 / 6 / 23$ & 0.905 \\
\hline \multicolumn{4}{|l|}{ Laboratory data } \\
\hline $\mathrm{Hb}(\mathrm{g} / \mathrm{dL})$ & $10.8 \pm 1.5$ & $10.8 \pm 2.1$ & 0.949 \\
\hline $\mathrm{Alb}(\mathrm{g} / \mathrm{dL})$ & $3.6 \pm 0.5$ & $3.5 \pm 0.6$ & 0.855 \\
\hline T-bil (mg/dL) & $0.9 \pm 0.5$ & $1.0 \pm 0.9$ & 0.644 \\
\hline $\mathrm{Na}(\mathrm{mEq} / \mathrm{L})$ & $140 \pm 4$ & $138 \pm 6$ & 0.102 \\
\hline $\mathrm{K}(\mathrm{mEq} / \mathrm{L})$ & $4.3 \pm 0.8$ & $4.6 \pm 0.7$ & 0.152 \\
\hline BUN (mg/dL) & $28.4 \pm 12.5$ & $36.1 \pm 14.6$ & $0.035^{*}$ \\
\hline Cre $(\mathrm{mg} / \mathrm{dL})$ & $1.44 \pm 0.50$ & $1.72 \pm 0.83$ & 0.133 \\
\hline eGFR $\left(\mathrm{mL} / \mathrm{min} / 1.73 \mathrm{~m}^{2}\right)$ & $36.1 \pm 12.0$ & $34.2 \pm 15.0$ & 0.598 \\
\hline $\mathrm{BNP}(\mathrm{pg} / \mathrm{mL})$ & $873 \pm 712$ & $1260 \pm 970$ & 0.093 \\
\hline \multicolumn{4}{|l|}{ Echocardiographic data } \\
\hline LVDd (mm) & $55.6 \pm 11.5$ & $56.4 \pm 11.7$ & 0.788 \\
\hline LVDs (mm) & $40.7 \pm 11.5$ & $42.1 \pm 13.2$ & 0.670 \\
\hline $\mathrm{EF}(\%)$ & $50.2 \pm 13.6$ & $50.9 \pm 15.2$ & 0.842 \\
\hline Underlying Heart Disease & & & 0.684 \\
\hline Ischemic heart disease & $10(37 \%)$ & $4(13 \%)$ & \\
\hline Hypertensive heart disease & $9(33 \%)$ & $11(36 \%)$ & \\
\hline Cardiomyopathy & $2(7 \%)$ & $9(29 \%)$ & \\
\hline Valvular heart disease & $6(22 \%)$ & $7(23 \%)$ & \\
\hline HFpEF ( $\geq 50 \%)$ & $16(59 \%)$ & $20(65 \%)$ & 0.788 \\
\hline \multicolumn{4}{|l|}{ Medications at admission } \\
\hline ACE-I/ARB & $24(89 \%)$ & $27(87 \%)$ & 1.000 \\
\hline Beta-blocker & $15(56 \%)$ & $19(61 \%)$ & 0.790 \\
\hline $\mathrm{CCB}$ & $9(33 \%)$ & $12(39 \%)$ & 0.786 \\
\hline Loop diuretic & $26(96 \%)$ & $31(100 \%)$ & 0.466 \\
\hline Spironolactone & $14(52 \%)$ & $15(48 \%)$ & 1.000 \\
\hline Thiazide & $5(19 \%)$ & $9(29 \%)$ & 0.378 \\
\hline Tolvaptan & $0(0 \%)$ & $0(0 \%)$ & 1.000 \\
\hline AAD & $5(19 \%)$ & $5(16 \%)$ & 1.000 \\
\hline Digoxin & $3(11 \%)$ & $6(19 \%)$ & 0.481 \\
\hline
\end{tabular}

BMI, body mass index; HT, hypertension; DM, diabetes mellitus; DL, dyslipidemia; CKD, chronic kidney disease; PCI, percutaneous coronary intervention; $\mathrm{CABG}$, coronary artery bypass grafting; HF, heart failure; SBP, systolic blood pressure; DBP, diastolic blood pressure; Pulse P, pulse pressure; HR, heart rate; CS, clinical scenario; NYHA, New York Heart Association; BNP, brain natriuretic peptide; LVDd, left ventricular enddiastolic diameter; LVDs, left ventricular end-systolic diameter; EF, ejection fraction; MR, mitral regurgitation; HFpEF, heart failure with preserved ejection fraction; ACE-I, angiotensin converting enzyme inhibitor; ARB, angiotensinII receptor blocker; $\mathrm{CCB}$, calcium channel blocker; AAD, antiarrhythmic drugs.

conventional group, it had declined at discharge $(-7.4 \pm$ 10.4).

\subsection{Changes in medication dose}

The dose of loop diuretics was higher $(+17.8 \pm 12.4)$ at 6 months after discharge in the TLV group than in the conventional group $(p=0.02)$ (Table 4$)$. There were no significant differences in cardio-protective medications, such as angiotensin-converting enzyme inhibitors and, beta-blockers, between admission and 6-months after discharge in either group (Table 3).

\subsection{Changes in clinical data}

The observed changes in clinical data are shown in Table 4. NYHA classification improved between baseline and discharge in both groups. There were 
Table 2. Treatment during the acute phase

\begin{tabular}{lccc}
\hline Items & Conventional group, $n=27$ & TLV group, $n=31$ & $p$-value \\
\hline NIPPV & $3(11 \%)$ & $5(16 \%)$ & 0.712 \\
Carperitide & $4(15 \%)$ & $2(6 \%)$ & 0.402 \\
Nitrate & $8(30 \%)$ & $6(19 \%)$ & 0.540 \\
Nicorandil & $1(4 \%)$ & $1(3 \%)$ & 0.087 \\
Catecholamine & $2(7 \%)$ & $31(100 \%)$ & 1.000 \\
Furosemide infusion & $27(100 \%)$ & & 0.000 \\
\hline
\end{tabular}

NIPPV, non-invasive positive airway pressure ventilation.

Table 3. Medications used after 6 months of follow-up

\begin{tabular}{lccc}
\hline Items & Conventional group, $n=27$ & TLV group, $n=31$ & $p$-value \\
\hline ACE-I/ARB & $24(89 \%)$ & $27(87 \%)$ & 1.000 \\
Beta-blocker & $15(56 \%)$ & $19(61 \%)$ & 0.790 \\
CCB & $9(33 \%)$ & $12(39 \%)$ & 0.786 \\
Loop diuretic & $26(96 \%)$ & $31(100 \%)$ & 0.466 \\
Spironolactone & $14(52 \%)$ & $15(48 \%)$ & 1.000 \\
Thiazide & $5(19 \%)$ & $9(29 \%)$ & 0.378 \\
Tolvaptan & 0 & $31(100 \%)$ & $0.000^{*}$ \\
AAD & $5(19 \%)$ & $5(16 \%)$ & 1.000 \\
Digoxin & $3(11 \%)$ & $6(19 \%)$ & 0.481
\end{tabular}

ACE-I, angiotensin-converting enzyme inhibitor; ARB, angiotensin II receptor blocker; CCB, calcium channel blocker; AAD, anti-arrhythmic drugs.

Table 4. Changes in clinical data

\begin{tabular}{|c|c|c|c|}
\hline Conventional group & Baseline & At discharge & $6 \mathrm{M}$ \\
\hline $\mathrm{eGFR}\left(\mathrm{mL} / \mathrm{min} / 1.73 \mathrm{~m}^{2}\right)$ & $36.1 \pm 12.0$ & $37.7 \pm 16.5$ & $30.3 \pm 9.2 *$ \\
\hline Tolvaptan (mg) & 0 & 0 & 0 \\
\hline Dose of loop diuretics (mg) & $24.4 \pm 21.9$ & $45.9 \pm 30.9$ & $43.3 \pm 29.0$ \\
\hline NYHA (I/II/III/IV) & $0 / 0 / 2 / 25$ & $21 / 6 / 0 / 0$ & $24 / 2 / 1 / 0$ \\
\hline $\mathrm{EF}(\%)$ & $50.2 \pm 13.6$ & - & $52.3 \pm 22.4$ \\
\hline $\mathrm{BNP}(\mathrm{pg} / \mathrm{mL})$ & $873 \pm 712$ & $409 \pm 444$ & $504 \pm 335$ \\
\hline TLV group & Baseline & At discharge & $6 \mathrm{M}$ \\
\hline $\mathrm{eGFR}\left(\mathrm{mL} / \mathrm{min} / 1.73 \mathrm{~m}^{2}\right)$ & $34.2 \pm 14.9$ & $36.1 \pm 14.9$ & $35.1 \pm 16.9$ \\
\hline Tolvaptan (mg) & 0 & $6.4 \pm 3.8$ & $8.7 \pm 5.0$ \\
\hline Dose of loop diuretics (mg) & $38.1 \pm 28.9$ & $50.3 \pm 29.6$ & $68.1 \pm 42.0^{*}$ \\
\hline NYHA (I/II/III/IV) & $0 / 2 / 6 / 23$ & $23 / 7 / 1 / 0$ & $24 / 6 / 1 / 0$ \\
\hline $\mathrm{EF}(\%)$ & $50.9 \pm 15.2$ & - & $51.8 \pm 17.9$ \\
\hline $\mathrm{BNP}(\mathrm{pg} / \mathrm{mL})$ & $1,260 \pm 970$ & $680 \pm 489$ & $530 \pm 500$ \\
\hline
\end{tabular}

NYHA, New York Heart Association; EF, ejection fraction; BNP, brain natriuretic peptide; ${ }^{*} p<0.05$ versus at discharge in the same group.
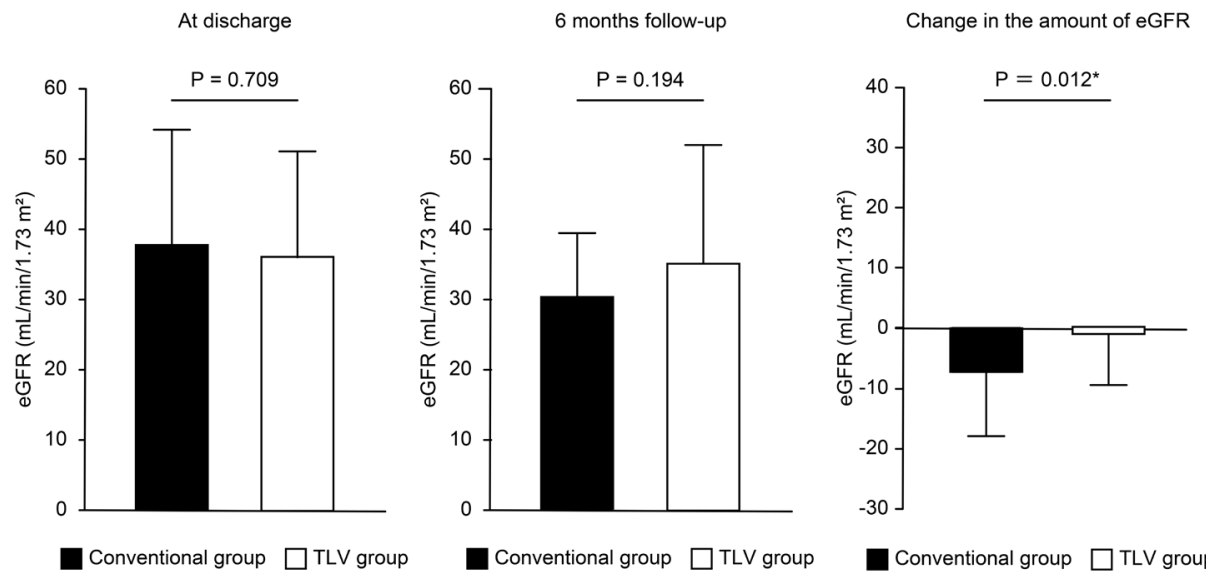

Figure 1. Changes in eGFR between the time of hospital discharge and 6 months later. During this period, there were no significant differences in eGFR in the TLV group, whereas eGFR significantly declined in the conventional group after 6 months of follow-up. The right graph shows a comparison of the changes observed in eGFR between the Conventional and TLV groups. The TLV group exhibited approximately the same eGFR $(-1.1 \pm 8.3)$, while eGFR declined in the conventional group $(-7.4 \pm 10.4)$. 
Table 5. Clinical outcomes

\begin{tabular}{lccc}
\hline Items & Conventional group & TLV group & $p$-value \\
\hline All-cause death & $0(0 \%)$ & $0(0 \%)$ & 1.000 \\
Cardiac death & $0(0 \%)$ & $0(0 \%)$ & 1.000 \\
Heart failure hospitalization & $8(30 \%)$ & $9(29 \%)$ & 1.000 \\
\hline
\end{tabular}

no significant differences between the two groups in the changes in clinical data that occurred between discharge and 6 months later. There were no significant differences in EF between baseline and after 6 months of follow-up. BNP was improved in both groups between baseline and discharge. There were no significant differences in the changes that occurred from discharge to 6 months later between the groups. The observed clinical outcomes are shown in Table 5. The frequency of hospitalization for HF was not significantly different between the groups.

\section{Discussion}

This study investigated the clinical effect of long-term administration of tolvaptan in HF patients with CKD. All patients in this study were dependent on high doses of diuretics for long-term periods of time. Although dose of loop diuretics was increased at 6 months follow-up, renal function did not worsen in TLV group.

Several studies have shown that renal function is an important factor when considering a prognosis for HF $(19,20)$. Consequently, preserving renal function is a primary objective in patients with $\mathrm{HF}$. The protective effects exerted by tolvaptan on renal function are likely attributable to several mechanisms. Specifically, Costello-Boerrigter et al. reported that renal blood flow and GFR were not reduced by tolvaptan (21). In addition, the diuretic effects of tolvaptan may prevent the deterioration of eGFR by ameliorating congestive kidney failure without activating the reninangiotensin system (22-24). In this study, the dose of furosemide was higher in the TLV group. Tolvaptan may therefore exert its renal-protecting effect even in patients administered high doses of furosemide. Renal congestion leads to increased renal interstitial pressure, which affects the entire capillary bed and tubules and can potentially induce local hypoxia. Tubular compression raises luminal pressure, further attenuating the transglomerular pressure gradient, and lowering the GFR (25). Tolvaptan is thought to improve renal congestion without promoting renal failure because it affects water diuresis from interstitial tissue. Unfortunately, there is no direct method to assess renal congestion, and causal relationships between chronically administered of tolvaptan and improvements in renal congestion were therefore not investigated in this study.

As no side effect and electrolyte imbalance were observed after chronic administration of tolvaptan, chronic administration of tolvaptan could be a safe treatment for HF patients with CKD.

Several studies have reported that long-term administration of tolvaptan reduced the frequency of admission for HF $(26,27)$. However, the frequency of hospitalization for HF was not significantly different between the groups in this study. The dose of loop diuretics is considered a predictor of hospitalization for HF and was significantly higher in the TLV group, which may have affected this outcome $(28,29)$. All patients had previously been hospitalized for ADHF and CKD. Previous studies have shown that a past history of hospitalization for HF is an independent risk factor for cardiovascular death in HF patients (30). Additionally, CKD is reportedly an independent risk factor for adverse outcomes in HF patients (19). As mentioned above, the patients in this study were considered to have poor prognoses. Moreover, indications for administration of tolvaptan were left to the discretion of the physician. The TLV group might have had a more severe background. This outcome should be confirmed in a further prospective large-scale study.

Our study has several limitations. 1) This was a retrospective observational study, and a small number of patients in a single center were included. 2) Patient characteristics were not identified. 3) The indications for long-term administration of tolvaptan were left to the discretion of the physician.

In conclusion, the results of our study suggest that chronic administration of tolvaptan may prevent increased renal dysfunction in HF patients with CKD and prior history of HF. Tolvaptan could be a safe and useful diuretic for HF patients with CKD. This conclusion should be confirmed in a future prospective study.

\section{References}

1. Chen HH, Redfield MM, Nordstrom LJ, Cataliotti A, Burnett JC Jr. AngiotensinII AT1 receptor antagonism prevents detrimental renal actions of acute diuretic therapy in human heart failure. Am J Physiol Renal Physiol. 2003; 284:F1115-1119.

2. Gottlieb SS, Brater DC, Thomas I, Havranek E, Bourge R, Goldman S, Dyer F, GomezM, Bennett D, Ticho B, Beckman E, Abraham WT. BG9719 (CVT-124), an A1 adenosine receptor antagonist, protects against the decline in renal function observed with diuretic therapy. Circulation. 2002; 105:1348-1353.

3. Vallon V. Tubuloglomerular feedback and the control 
of glomerular filtration rate. News Physiol Sci. 2003; 18:169-174.

4. Cooper HA, Dries DL, Davis CE, Shen YL, Domanski MJ. Diuretics and risk of arrhythmic death in patients with left ventricular dysfunction. Circulation. 1999; 100:1311-1315.

5. Domanski M, Norman J, Pitt B, Haigney M, Hanlon S, Peyster E. Studies of Left Ventricular Dysfunction. Diuretic use, progressive heart failure, and death in patients in the Studies Of Left Ventricular Dysfunction (SOLVD). J Am Coll Cardiol. 2003; 42:705-708.

6. Abdel-Qadir HM, Tu JV, Yun L, Austin PC, Newton GE, Lee DS. Diuretic dose and long-term outcomes in elderly patients with heart failure after hospitalization. Am Heart J. 2010; 160:264-271.e261.

7. Yamamura Y, Nakamura S, Itoh S, et al. OPC-41061, a highly potent human vasopressin $\mathrm{V}_{2}$-receptor antagonist: Pharmacological profile and aquaretic effect by single and multiple oral dosing in rats. J Pharmacol Exp Ther. $1998 ; 287: 860-867$

8. Hirano T, Yamamura Y, Nakamura S, Onogawa T, Mori $\mathrm{T}$. Effects of the $\mathrm{V}_{2}$-receptor antagonist OPC-41061 and the loop diuretic furosemide alone and in combination in rats. J Pharmacol Exp Ther. 2000; 292:288-294.

9. Vaduganathan M, Gheorghiade M, Pang PS, Konstam MA, Zannad F, Swedberg K, Grinfeld L, Burnett JC Jr, Krasa HB, Zimmer C, Blair J, Ouyang J, Maggioni AP; EVEREST investigators. Efficacy of oral tolvaptan in acute heart failure patients with hypotension and renal impairment. J Cardiovasc Med (Hagerstown). 2012; $13: 415-422$

10. Matsue Y, Suzuki M, Seya M, Iwatsuka R, Mizukami A, Nagahori W, Ohno M, Matsumura A, Hashimoto Y. Tolvaptan reduces the risk of worsening renal function in patients with acute decompensated heart failure in highrisk population. J Cardiol. 2013; 61:169-174.

11. Gheorghiade M, Gattis WA, O'Connor CM, Adams KF Jr, Elkayam U, Barbagelata A, Ghali JK, Benza RL, McGrew FA, Klapholz M, Ouyang J, Orlandi C; Acute and Chronic Therapeutic Impact of a Vasopressin Antagonist in Congestive Heart Failure (ACTIV in CHF) Investigators. Effects of Tolvaptan, a vasopressin antagonist, in patients hospitalized with worsening heart failure. JAMA. 2004; 291:1963-1971.

12. Gheorghiade M, Orlandi C, Burnett JC, Demets D, Grinfeld L, Maggioni A, Swedberg K, Udelson JE, Zannad F, Zimmer C, Konstam MA. Rationale and design of the multicenter, randomized, double-blind, placebo-controlled study to evaluate the efficacy of vasopressin antagonism in heart failure: Outcome study with tolvaptan (EVEREST). J Card Fail. 2005; 11:260269.

13. Blair JE, Pang PS, Schrier RW, et al. Changes in renal function during hospitalization and soon after discharge in patients admitted for worsening heart failure in the placebo group of the EVEREST trial. Eur Heart J. 2011; 32:2563-2572.

14. Konstam MA, Gheorghiade M, Burnett JC Jr, Grinfeld L, Maggioni AP, Swedberg K, Udelson JE, Zannad F, Cook T, Ouyang J, Zimmer C, Orlandi C; Efficacy of Vasopressin Antagonism in Heart Failure Outcome Study with Tolvaptan (EVEREST) Investigators. Effects of oral tolvaptan in patients hospitalized for worsening heart failure: The EVEREST outcome trial. JAMA. 2007; 297:1319-1331.
15. Kinugawa K, Sato N, Inomata $\mathrm{T}$, Shimakawa $\mathrm{T}$, Iwatake N, Mizuguchi K. Efficacy and safety of tolvaptan in heart failure patients with volume overload. Circ J. 2014; 78:844-852.

16. Matsuo S, Imai E, Horio M, Yasuda Y, Tomita K, Nitta K, Yamagata K, Tomino Y, Yokoyama H, Hishida A. Collaborators developing the Japanese equation for estimated GFR. Revised equations for estimated GFR from serum creatinine in Japan. Am J Kidney Dis. 2009; 53:982-992.

17. Iseki K. Chronic kidney disease in Japan. Intern Med. 2008; 47:681-689.

18. Krück F, Bablok W, Besenfelder E, Betzien G, Kaufmann B. Eur J Clin Pharmacol. 1978; 14:153 -161.

19. Hamaguchi S, Tsuchihashi-Makaya M, Kinugawa S, Yokota T, Ide T, Takeshita A, Tsutsui H; JCARE-CARD Investigators. Chronic kidney disease as an independent risk for long-term adverse outcomes in patients hospitalized with heart failure in Japan. Report from the Japanese Cardiac Registry of Heart Failure in Cardiology (JCARE-CARD). Circ J. 2009; 73:1442-1447.

20. Hosoda J, Ishikawa T, Matsushita K, Matsumoto K, Kimura Y, Miyamoto M, Ogawa H, Takamura T, Sugano T, Ishigami T, Uchino K, Kimura K, Umemura $\mathrm{S}$. Impact of renal insufficiency on long-term clinical outcome in patients with heart failure treated by cardiac resynchronization therapy. J Cardiol. 2012; 60:301-305.

21. Costello-Boerrigter LC, Smith WB, Boerrigter G, Ouyang J, Zimmer CA, Orlandi C, Burnett JC Jr. Vasopressin-2-receptor antagonism augments water excretion without changes in renal hemodynamics or sodium and potassium excretion in human heart failure. Am J Physiol Renal Physiol. 2006; 290:F273-278.

22. Mullens W, Abrahams Z, Francis GS, Sokos G, Taylor DO, Starling RC, Young JB, Tang WH. Importance of venous congestion for worsening of renal function in advanced decompensated heart failure. J Am Coll Cardiol. 2009; 53:589-596.

23. Okada T, Sakaguchi T, Hatamura I, Saji F, Negi S, Otani H, Muragaki Y, Kawachi H, Shigematsu T. Tolvaptan, a selective oral vasopressin $\mathrm{V}_{2}$ receptor antagonist, ameliorates podocyte injury in puromycin aminonucleoside nephrotic rats. Clin Exp Nephrol. 2009; 13:438-446.

24. Onogawa T, Sakamoto Y, Nakamura S, Nakayama S, Fujiki H, Yamamura Y. Effects of tolvaptan on systemic and renal hemodynamic function in dogs with congestive heart failure. Cardiovasc Drugs Ther. 2011; 25(Suppl1):S67-76.

25. Afsar B, Ortiz A, Covic A, Solak Y, Goldsmith D, Kanbay M. Focus on renal congestion in heart failure. Clin Kidney J. 2016; 9:39-47.

26. Imamura $\mathrm{T}$, Kinugawa $\mathrm{K}$. Tolvaptan Improves the LongTerm Prognosis in Patients With Congestive Heart Failure With Preserved Ejection Fraction as Well as in Those With Reduced Ejection Fraction. Int Heart J. 2016; 57:600-606.

27. Kiuchi S, Fujii T, Hisatake S, Kabuki T, Takashi O, Dobashi S, Ikeda T. Experience with long-term administration of tolvaptan to patients with acute decompensated heart failure. Drug Discov Ther. 2017; $11: 133-139$

28. Eshaghian S, Horwich TB, Fonarow GC. Relation of loop diuretic dose to mortality in advanced heart failure. Am J Cardiol. 2006; 97:1759-1764. 
29. Hasselblad V, Gattis Stough W, Shah MR, Lokhnygina Y, O'Connor CM, Califf RM, Adams KF Jr. Relation between dose of loop diuretics and outcomes in a heart failure population: Results of the ESCAPE trail. Eur J Heart Fail. 2007; 9:1064-1069.

30. Bello NA, Claggett B, Desai AS, McMurray JJ, Granger CB, Yusuf S, Swedberg K, Pfeffer MA, Solomon SD.
Influence of previous heart failure hospitalization on cardiovascular events in patients with reduced and preserved ejection fraction. Circ Heart Fail. 2014; 7:590595.

(Received February 6, 2018; Revised May 6, 2018; Accepted June 16, 2018) 